\title{
Expert Patients and Human Agency: Long-term Conditions and Giddens' Structuration Theory
}

\section{IAN GREENER}

School of Applied Social Sciences, University of Durham, 32 Old Elvet, Durham DH1 3HN, UK. E-mail: ian.greener@durham.ac.uk

\begin{abstract}
This paper critically examines the UK government's approach to long-term sickness, the 'Expert Patient', examining its relationship to the 'Third Way' project, its social theoretical underpinnings, the motivations for wishing to introduce it and the dangers of assuming that the pilot studies that have been carried out in the US and UK for the scheme are generalisable across the population of those with long-term conditions. Instead, it considers the nature of the dependent relationship between the long-term ill and the state, and asks why governments have come to be so averse to it, and asks who should be responsible for care decisions in healthcare. Social Theory \& Health (2008) 6, 273-290. doi:10.1057/sth.2008.11
\end{abstract}

Keywords: self-care; long-term conditions; agency; structure; Hoggett

\section{INTRODUCTION}

There is something of a quiet revolution going on in the care of long-term conditions in the UK. Between 1999 and 2001, the government tried to place an emphasis on the development of self-management capacity in the area of long-term illness through the use of a new idea, a new model of care. The 'Expert Patient' was introduced in the 1999 White Paper 'Our Healthier Nation' on the ground that previous care strategies had been judged to have failed to 'recognise how people can play a positive part in building healthy lives for themselves and in contributing to the health of other members of society' (Department of Health, 1999, Section 3.2). This approach was further elaborated through the publication of 'The Expert Patient: A New Approach to Chronic Disease Management for the 21st Century' 2 years later (Department of Health, 2001b) and has become, with very little attention, a central part of the dynamic of the new market for care in the National Health Service (NHS) 
that actively relies on the widespread introduction of the Expert Patient care model to work (Wilson et al., 2005). This paper contends that the approach to long-term care in the 'Expert Patient' is deeply flawed, in that it is a view of the patient that is unsustainably reflexive, and reflects an error in social theory that is shared by Giddens' structuration theory (Giddens, 1979, 1984; Thompson, 1989). The paper presents a critique of both the Expert Patient programme and Giddens' work, incorporating Hoggett's work on dependency (Hoggett, 2000), asking why the approach has appeared at this specific time, and problematising its use in the context of recent evidence and evaluations of its use.

\section{THE INTRODUCTION OF THE EXPERT PATIENT}

This will be an ambitious and challenging programme for the NHS. It has long been recognised that people with chronic diseases have considerable knowledge and experience of their own illness. Research has shown that with proper training this can be turned into practical skills to enable the patient to play a bigger part in managing their own condition.

The new Expert Patients programme will help to create a new generation of patients who are empowered to take action with the health professional caring for them to reduce pain, improve the use of medication and improve their overall quality of life. Patients will receive the support to help them take more control of their own health and treatment, to make more appropriate use of health and social services and feel empowered in their relationship with healthcare professionals.

Professor Liam Donaldson, Chief Medical Officer, 14 September 2001

The quote above from the Chief Medical Officer at the launch of 'The Expert Patient' (Department of Health, 2001b) attempts to make clear the benefits of utilising a new approach to the treatment of long-term conditions. The idea is a striking one; the state will empower Expert Patients by providing resources to meet the needs of those with long-term illnesses, while at the same time encouraging that group to self-care and manage their own condition. It will, claims the Chief Medical Officer, usher in a 'new era' for the NHS (Donaldson, 2003). In the constant revolution of New Labour health policy, it is easy to not notice the release of yet another policy document, and so underestimate the significance of the change in care practices present within the document. But the Expert Patient represents the most concerted effort yet to introduce self-care into the NHS and to create the 'active patient' central to governmental ideas about patient choice and patient empowerment (Department of Health, 2002). 
The 'Expert Patient' is not only an approach that challenges preconceptions about the nature of medical knowledge and power, assuming that patients can self-manage their conditions to a far greater extent than at present. It also suggests that medical knowledge can be appropriated by patients with long-term conditions and supplemented by lay knowledge acquired from self-help groups.

There is presently only a limited amount of research on the Expert Patient, mostly appearing in the nursing literature, and which attempts to explore the considerations that the policy carries for changing practice in treatment regimes (Gaze, 2000; Illman, 2000; Wilson, 2001) or for power relationships in nurse/patient relationships (Wilson et al., 2006). However, enough research has now been completed to begin to assess the prospects for achieving the very lofty goals set for it.

\section{EVIDENCE FOR AND AGAINST THE EXPERT PATIENT}

The origin of the Expert Patient approach appears to come from studies of Lorig et al. (1996) that present an influential model of self-care from the United States (cited in Department of Health, 1999). Lorig's enthusiastic explications of the approach in UK journals have suggested, in line with 'Medical Self-Care Magazine', that 'doctors would get off their pedastals when patients got off their knees’ (Lorig, 2002, p. 815).

Based on what they term 'Social-Psychological Theory' of 'Self-Efficacy', three principles underpin the approach of Lorig and her colleagues. First, that 'the strength of one's capability to do a specific task or achieve a certain behaviour is a good predictor of motivation and behaviour' (p. 5). There is good sense in this, even if it is less clear exactly how to sensibly measure these factors. Second, 'One's self-efficacy belief can be enhanced through performance mastery, modelling, reinterpretation of symptoms and social persuasion'. This is slightly more concerning; there seems to be an assumption here that symptoms might be made to go away through self mastery, with the 'performance' of long-term conditions becoming as important as their presence. The third principle extends this, 'Enhanced self-efficacy leads to improved behaviour, motivation, thinking patterns and emotional well-being' (p. 6). The link between the approach to dealing with long-term conditions and quality of life is not disputed here, but it is surely sensible to question the extent to which one might be 'managed' in this way.

The Chronic Disease Self Management Programme (CDSMP) (Department of Health, 2001b, p. 25) lists five key management skills strongly influenced by Lorig's work; 'problem-solving, decision-making, resource 
utilisation, formation of a patient-professional partnership and taking action'. It then notes that the real key to effective self-management is 'the change to the individual's confidence and belief that they can indeed take control over their life despite their disease' (p. 25). The five self-management skills comprise a 'toolkit' for the patient then to deploy as required. It would seem that, with a little management training (the analogy with the managerial state (Clarke and Newman, 1997) is quite striking), those with long-term conditions must take greater responsibility for themselves. They will then have the confidence (and the self-discipline) to deal with whatever life and their condition brings.

In arthritis trials in the UK, the use of self-care has been extensively evaluated as providing increased psychological well-being, improving communication with health professionals and also reducing the number of visits to general practitioners' (GP) surgeries (Barlow and Barefoot, 1996; Barlow and Williams, 1999; Barlow et al., 1999). Patients often managed to reduce their reported pain levels, producing a positive benefit, while at the same time producing a practical incentive for policymakers to extend the scheme because of the potential reduction in demand for scarce health resources that might result. The political context within which this policy has occurred has also been a favourable one toward it; long-term health needs have been redefined as being at least partially the responsibility of local authorities because of their 'social' as opposed to 'medical' construction (Twigg, 1997), and there has been an increased use of private healthcare to fill the gap left by the state's partial withdrawal. As well as this, the population has been increasingly urged to lead a healthier lifestyle (Department of Health, 1999, 2004; Secretary of State for Health, 1992), attempting to place a greater onus on individual discipline in creating better health outcomes to take greater responsibility for 'health' as opposed to 'illness' (Peterson and Lupton, 1996).

If the research upon which the Expert Patient programme was based appeared remarkably successful, then subsequent evaluations have not offered as much of an endorsement. The national evaluation of the Expert Patient Pilot programme found very little in terms of cost-saving as a result of the programme. There were, however, 'moderate' gains in self-efficacy and small gains in energy, but no impacts on routine health service use - in fact, there were increases in out-of-pocket costs coming from an increased use of alternative therapies and home helps. Those on the Expert Patient programme did enjoy it though (Rogers et al., 2006).

There also seems to have been a very low take-up of the Expert Patient programme in many areas. Wootton et al. (2008) argue that this is due to a lack of awareness of the programme as well as a relatively small number of 
patients being suitable for it. They do, however, suggest that those that do end up on the programme gain 'empathy and support' (p. 84) from it. Equally, Swift and Dieppe (2005) suggest that Expert Patients can learn to express themselves and share experiences if their narratives are published in booklets for one another. Gaining empathy and sharing experiences has much to commend it, but if the goal of the Expert Patient programme is about engendering autonomy, this is a very different outcome. Shaw and Baker (2004) argue that the term 'Expert Patient' needs to be dropped because patient expertise lies in their 'views and situation' (p. 724) rather than in medical expertise, which will only apply to a 'minority of patients' (p. 724).

Given the lack of success in implementing the Expert Patient, why does it seem such common sense to policymakers? Given the scale of long-term illness in the UK, there is clearly a strong managerial incentive to free up care resources if at all possible. But this is not the only reason. The Expert Patient, as well as producing ambiguous or even poor evaluations so far, also carries with it ideological baggage, the questioning of which is difficult for policymakers as it calls into question the bases of reforms across the whole of the welfare state. The analysis below will attempt to demonstrate this.

\section{HUMAN AGENCY AND SOCIAL POLICY}

There has been something of a revival of interest in the role of human agency in social policy in recent years (Deacon and Mann, 1999; Greener, 2002; Hoggett, 2001; Le Grand, 1997; Taylor-Gooby et al., 2000). This is a welcome incursion of the world of social theory into social policy, making explicit the assumptions policymakers often hold concerning the nature of welfare recipients who can cast new light upon the policymaking process and also upon the likely success of the policies produced. To find the biggest social-theoretical influence on New Labour we do not have to look far. Anthony Giddens, coiner of the term 'The Third Way' (Giddens, 1998), is regarded as being the government's favourite academic and continues to produce texts holding some considerable influence over its policy direction (Giddens, 2002, 2007). Underpinning much of his analysis is Giddens' distinctive approach to understanding the relationship between human agency and the structural constraints or opportunities that provide the context within which action occurs.

The next section will consider Giddens' structuration theory and attempt to draw out the implications of placing the approach at the heart of the Expert Patient reform through a detailed analysis of its main policy document (Department of Health, 2001a). It then presents an alternative view, reconsidering the role of 'dependency' in welfare policy, before presenting a conclusion. 


\section{Giddens' structuration theory}

Giddens' theory of structuration (Giddens, 1979, 1984; Thompson, 1989) is designed to 'illuminate the duality and dialectical interplay of agency and structure' (Bernstein, 1989, p. 23). It does this through the analysis of human practices, which he insists are recursive, so that activities are 'not brought into being by social actors but are continually recreated by them via the very means whereby they express themselves as actors, In and through their activities agents produced the conditions that make these activities possible' (Giddens, 1984, p. 2). It is through recursive practices that social structures are reproduced, effectively turning agency and structure into two sides of the same coin, two elements of the same combined whole. By focusing on the recursive nature of practice, Giddens suggests that structures and practices are reproduced both temporally and geographically. This process is not habitual, as human actors are not merely self-conscious, but also engaged in monitoring so that 'agency itself is reflexively and recursively implicated in social structures' (Bernstein, 1989, p. 23). Agency and structures are bound by history in a processual and dynamic way rather than being the result of inherited power structures or unreflexive habitual behaviour.

Actors, according to Giddens, develop routines that provide them with a sense of security and enable them to deal with the complexity of their social lives. Giddens differentiates between practical consciousness, which involves actions that actors take for granted, and discursive consciousness, which is the ability of the actor to describe actions in words. Practical consciousness allows Giddens' analysis to move from agents to agency through to action, and demonstrates structuration theory's emphasis on what is done rather than what is said (Ritzer, 1996). Giddens suggests that actors have considerable potential to make a difference, either intentionally or unintentionally, in the social world. They have choices as well as constraints, and because they have choices and the ability to act, they have power. Not all action is purposeful, but much action is 'purposive', in the sense that it is monitored by actors who survey what they are doing, what its effects are on others and in what circumstances they are acting (Thompson, 1989). Discursive consciousness implies that individuals are knowledgeable agents who can account for their actions and know a great deal about the world in which they act. This is Giddens' model of human agency - a positive, empowering one. The price of this appears to be a lack of clarity over the role of structures in society.

Giddens provides an unusual definition of social structures, basing the definition around rules and resources (Giddens, 1984, p. 17; Thompson, 1989, p. 62) and also making the claim that structure only exists in and through the activities of human agents. Structure is in no way external to 
human action, it is what gives shape or form to human life but 'not itself that form and shape' (Giddens, 1989, p. 256, italics in original). Structure is always both constraining and enabling. Structures are not only reproduced through practice as social systems, they are 'instantiated' as such, but they are also manifested in the 'memory traces orienting the conduct of human agents' (Giddens, 1984, p. 17). The structural properties of social systems are therefore the 'outcome of the practices they recursively organise' (Giddens, 1984 , p. 25). For Giddens, the social system is 'the product of a stable personality working routinely. Social order exists only because we are creatures of habit' (Craib, 1992, p. 158), but, as noted above in the section of agency, it is possible to escape from habitual behaviour through reflexivity, effectively dissolving structures as a result.

Social structures, then, represent the flip side of the coin to agency, but are defined in Giddens' work in an unusual way. This element of his work has also attracted a considerable amount of criticism. Thompson (1989, pp. 62-66) makes a number of points that essentially distil into asking: how can structures exist that are based around rules that have no basis in the 'social structure which is separate from the study of those rules that are singled out in its name?' (p. 65). In Giddens' view it seems that there is very little to restrain agency; the physical world is given some credibility as a potential location of agency limitation, but this element does not seem significant in much of his work (Craib, 1992, p. 161). Equally, it surely seems unrealistic to assume that social structures are effectively a shared cognitive phenomenon, ignoring the numerous forms of capital (symbolic, economic, cultural, etc, (Bourdieu, 1990, 1991, 1998)), that are typically found in society, and the allocations of which will considerably affect our life chances and trajectory (Archer, 1995).

Equally, it is not clear what limits to reflexivity Giddens' actors experience (Craib, 1992, p. 150; Hoggett, 2001, p. 39). Reflexivity allows actors to be able to understand and interact with their social world and is clear in Giddens' concept of the 'autotelic self', which is at the heart of his 'positive welfare' prescriptions (see especially Giddens, 1994a, pp. 192-194; Giddens, 1998). Within this, subjects seek to 'translate potential threats into rewarding challenges' (Giddens, 1994a, p. 192), not acknowledging the structural restraints upon actors because they appear to exist primarily cognitively.

Giddens' work on the 'risk society' (see especially Giddens, 1994b) suggests that scientific (or 'traditional') knowledge is coming increasingly under question as it intrudes ever more into our lives. People are increasingly required to make lifestyle choices that involve them in assessing and making calculations about the potential risks that affect our lives, and forcing a 
reflexivity of the self that is quite different from that which has been 'traditionally' required of them. The construction of the self is an ongoing project in an effort to construct ontological security (Giddens, 1991) that requires a process of reflexively organising evidence and information in order to strengthen or undermine our emotional security (Burrows and Nettleton, 2000). The search for answers to health problems outside of conventional medical encounters is a manifestation of this process. In the context of health, one supposes, it becomes necessary to analyse in detail our food and exercise regimes and assess their costs and benefits in terms of our well-being.

Of course, all of this would be important in the agenda of sociologists only, had 'The Third Way' not become such an important influence in the development, and subsequent policy, of New Labour in the UK (Westergaard, 1999). Despite the lack of empirical research examining the potential usefulness of structuration theory and the criticism that, in itself, it does not present a coherent social theory (Gregson, 1989, p. 248), it has become the underpinning of Labour's analysis of welfare and has direct links to the Expert Patient.

\section{Agency and the Expert Patient}

The Expert Patient policy document (Department of Health, 2001b) has several elements that show a strong fit with a view of the world derived from Giddens' work. As noted above, instead of placing its emphasis on health professionals to work with the long-term sick to manage conditions such as multiple sclerosis (MS), asthma or sickle cell anaemia, the Expert Patient appears to suggest that, with self-efficacy training, people with these types of conditions can take control of the management of their own care. Input from health professions should become less frequent, with patients reducing the level of medication they receive. Patients are, according to Chief Medical Officer Donaldson at the document's launch, to become 'empowered in their relationship with healthcare professionals'.

The flaws of Giddens' structuration theory are immediately apparent in 'The Expert Patient'. It assumes that the long-term sick are both able and willing to take control of the management of their own healthcare on the basis that health professionals have increasingly noted that 'my patients understand their disease better than I do' and that the knowledge and experience held by the patient 'has for too long been untapped resource' (Department of Health, 2001b, p. 5). This may well be the case for some patients; those with long-term conditions such as asthma or MS are often required to develop an in-depth knowledge of their conditions, their individual reactions to various medications, and to become more aware of 
'what works' for them than their doctor. However, whether it is generally the case remains a largely untested question.

One reason for patients to wish to take control of their own care is due to the still-poor information quality within the health service in the UK, where medical records routinely go missing and electronic systems are still so fragmentary as to put doctors often in the unenviable position of not having the full medical records of the patient before them available. In these circumstances, patients with long-term conditions may have more complete information than the doctors before them, which hardly serves to give them confidence in the decisions doctors are making. Equally, it is reasonable to suggest that long-term disease sufferers might often take a medical interest in their condition and develop a detailed knowledge of it, albeit one that is ultimately limited by a lack of knowledge of other medical areas.

But the Expert Patient document also appears to have an additional agenda that gradually becomes more apparent in the document. On page 26 it becomes clear that self-management programmes tend to mean that patients with asthma reduce the quantity of medication they use (it is not clear from the document alone whether this improved health or not), and on page 29 Table 1 appears.

Perhaps the most important point about all of these 'impacts' is their ambiguity. Viewed from a sympathetic perspective, the reduction in reliance on health professionals in Table 1 is an entirely positive phenomenon, with individuals taking responsibility for their own care and demonstrating health benefits as a result. This may be true for some of the 'self-management' patients, and is borne out by the arthritis self-care trials in the UK (see above). A more critical interpretation wonders what the health consequences of 'selfmanaging' patients not seeing health visitors, GPs and specialists might be. Can it be that those with long-term conditions have so much time to ponder

Table 1. Evidence for impact of self-management programmes on service use

\begin{tabular}{ll}
\hline $\begin{array}{l}\text { Health problem } \\
\text { Chronic pain Arthritis }\end{array}$ & $\begin{array}{l}\text { Impact on self-management programmes on care services } \\
\text { Rrthritis }\end{array}$ \\
$\begin{array}{l}\text { Reduction in the number of visits to health professionals up to } 80 \% \\
\text { Asthma }\end{array}$ & Reduction in the number of GP visits up to $44 \%$ \\
Sickle cell disease and & $\begin{array}{l}\text { Reduction in the number of hospitalisations (up to } 31 \% \text { ) and length of stay } \\
\text { (upthma } 50 \% \text { ) }\end{array}$ \\
Insomnia & $\begin{array}{l}\text { Reduction in number of visits to specialists by } 15 \% \\
\text { Sickle cell disease and }\end{array}$ \\
Asthma & $\begin{array}{l}\text { Reduction in number of accidents and emergency department visits up to } \\
\text { Asthe }\end{array}$
\end{tabular}

(Department of Health, 2001b, p. 29). 
their condition that they make unnecessary trips to see doctors at the moment, or that doctors hard-pressed for time interfere when it is not necessary in the treatment of their patients? This would appear to assume that patients are consuming health servicer resources irresponsibly and that doctors are happy to over-prescribe and refer, with the end result being an excessive amount of treatment taking pace. This is a patronising view of both the long-term sick and the medical profession, but one that appears to flow logically from the imperative of needing to get the new internal market to function.

The largely arbitrary time savings that the government appears to believe possible in the treatment of long-term conditions through the Expert Patient approach may be innocuous, but the belligerent way in which guidelines have been turned into targets in so many other areas (see, eg, Department of Health, 2001a) surely means any attempt at quantification by the Department of Health should be treated with extreme caution. Evidence from the Multiple Sclerosis Society (2003) suggests that those suffering from that condition require rather more medical support than they are receiving presently, not less. However, if the Expert Patient programme was introduced explicitly to achieve time savings, then its performance so far towards this goal has been extremely disappointing (Rogers et al., 2006).

So far the debate over long-term care has been framed solely in terms of treatment process and efficacy. But there is another motivation for the timing for its review in the United Kingdom; one in three of the population of the United Kingdom has a long-term condition of one kind or another (Department of Health, 1999). As people live longer, becoming more affected by degenerative diseases, the figure can only rise. The logic behind the Expert Patient approach is that, through experience of their condition, people acquire expert knowledge of their own specific medical needs, and so are well-placed to make decisions about their own treatment. When people acquire long-term conditions, such as asthma or MS, they develop experience in managing their condition, learning how to reduce the worst effects of the disease, and also to 'tailor' their own care package and drug usage. As such, they become experts in managing their own condition, an expertise often based not on book learning, but on their own daily care (Wilson, 2001).

The agenda of the Expert Patient does not simply encompass cost saving it goes beyond this. The 'new' internal market in the NHS is based around a local 'mixed economy' of health in which preferred private sector providers effectively compete with NHS Trusts in order to achieve the reduction in waiting lists required in the NHS Plan (Secretary of State for Health, 2000, 2002). The main purchasers in the new system are Primary Care Trusts, who must contract with the most efficient providers to drive the new market 
dynamic. This implies a considerable amount of resource discretion on the part of Primary Care Trusts - an ability to reallocate resources and take decisions in an efficiency-driven manner. But there is little evidence that decisions are made in this way (Greener and Powell, 2003) or that budgetary processes allow the reallocation of resources between providers to allow such a market to work (Greener and Mannion, 2006). The problem is that Primary Care Trusts must free up care resources in order to make the market work. Implicit within the agenda of freeing up resources is the Expert Patient policy. Unless the Expert Patient is a success, it is virtually impossible to see how the new healthcare marketplace can work.

The link between the new market for care in the Expert Patient programme is also brought out by Fox et al. (2005) in the context of their research on user groups in obesity. They find that the 'expert' part of Expert Patients is framed within a specific system of thought that is biomedical, and means that patients become 'reflexive, contextualising her life-story and experiences within available systems of thought, which - at least in policy formualtions - are biomedical' (p. 1307). In terms of obesity control, they find that patients learned about their condition within a set of pre-defined guidelines, locating available discourses within the biomedical model only. This is ironic as the Expert Patient in these terms does not mean a loss of power for clinicians, which the nursing literature particularly seems to fear, but instead means that debates are couched entirely in their terms.

Baker and Stern's (1993) study of the readiness to self-care in individuals with long-term conditions also asks difficult questions of the Expert Patient programme. Their findings suggest that if patients thought of themselves to be incapacitated or sick, they also considered themselves dependent, and so unable to self-care. If they sought symbolic meaning to their illness, alternatively, it might be possible to persuade the patient to reconsider their condition, so that asthma, far from being a barrier, might be minimised in impact by showing prominent athletes with the condition, or comparing the disease to more debilitating conditions. A third finding of the study was that individuals felt they were embarking upon 'unfamiliar trajectories' because of the permanent nature of long-term conditions, and the lifestyle change often associated with their contraction. If individuals sought miracle cures, scapegoats or simply gave up, they would also be unable to self-care. Given the range of situations where self-care seems not to work, it would suggest that the Expert Patient programme is going to be limited to a relatively small number of patients.

It may well be that a proportion of those with conditions such as asthma and MS may wish to take over responsibility for their medication, and have probably already done so. But that this is representative of the population as a 
whole cannot be assumed. This misplaced assumption is compounded by another error, that of a homogeneous category of people exist that can be called 'long-term sick', all of whom are both willing (although they may not be aware of this yet) and able to become self-managing in their care. Is it possible that such patients might actually be better off within a healthcare system that seems them more regularly, and where clinical decisions are made by those qualified to do so, doctors? It is striking that the CDSMP does not include education about the medical condition suffered by the patient, it is instead about the managerial skills that are necessary in order to cope with it, risking reducing complex illnesses to self-management problems.

\section{DISCUSSION - HEALTHCARE AGENCY AND THE EXPERT PATIENT}

The Expert Patient approach brings a central issue of healthcare agency to the fore: it is difficult for patients to manage their drug intake if they do not fully understand the process and implications of the condition from which they suffer. 'The Expert Patient' model assumes that patients already have this knowledge, but the 'expert' in the Expert Patient is based on experiential rather than medical knowledge. Under normal circumstances this may be safe and legitimate, but should the patient place him or herself in real danger, the lack of detailed medical knowledge may become dangerous very quickly. Lay beliefs are not separate from medical expert systems, but are, instead, likely to be heavily influenced by them (Shaw, 2002). They are likely to be fragmentary and disparate in a way that may not capture the complex character of their illness. This seems to place an unreasonable burden of reflexivity upon a patient who is often in the weakest position to locate such information as he or she is already burdened by a long-term condition. This is not to say that some patients with long-term conditions do not want to become self-managing, but because of the degree of reflexivity and confidence that it requires, they probably have already done so. As such, any attempt to persuade more of them to manage their own care is likely to be a fraught, and even possibly dangerous, process. If the reasons for doing this (and so, one presumes, the incentive to doctors to introduce the scheme) are to reduce visits to health professionals and medication bills, then this is an entirely dubious motive.

Equally, those participating in trials are most likely to be the patients already considering attempting self-medication, and so fall into a group that are relatively reflexive, possessing a good deal of information about the condition they had acquired already, are confident enough to administer their own drugs, and whose symptoms were not so acute as to prevent them from 
becoming Expert Patients. It is easy to imagine how a self-management system could quickly be subject to diminishing returns, with any expansion quickly resulting in patients who are too ill to be self-medicating, too medically ignorant of their condition to be safely left without medical supervision, or too lacking in reflexivity to adequately monitor their own conditions. In all three cases the results are potentially dangerous; where a patient lacks the confidence or competence to self-administer drugs, it could actually result in the medical profession having to increase its input into the care process rather than reduce it. An analogy with universities taking on students lacking the confidence and ability to deal with higher education springs to mind - this often seems to result in disproportionately high resources being required for students that fail quickly, and who often feel they have been almost fraudulently press-ganged into going to college.

For the Expert Patient approach to work among those patients who are both willing and able to take on the additional responsibilities involved, it must also assume that the structure of the medical provision of services is capable of producing the support that Expert Patients will need, and this will require a dramatic change in medical culture (Tattersall, 2002). The medical profession, in fact, may well be the target group of the Expert Patient document, in which case it becomes an attempt to change existing medical organisation and culture in order for the long-term sick to receive greater independence. But this, again, appears confused. Those patients who wish to be self-managing, probably are so already, have taken matters into their own hands. These are the highly reflexive agents also able to impose themselves upon their environment, taking full advantage of the medical services on offer to them. Other patients, however, may have less confidence, have GPs and consultants who are unwilling, for medical or cultural reasons, to relinquish control of treatment, or simply have a condition that has progressed to a stage where to become an Expert Patient is simply unfeasible.

A difficult question that this raises is who should make decisions about what is best for NHS patients? Individuals who have long-term conditions may, in some circumstances, feel they want independence, but if this is not in their best interests because it might damage their health, medical practitioners are being put in an extremely difficult position by the state. Where a doctor is preventing a patient's independence because of some outof-date principle that doctor always knows best, this is clearly not good enough. If, however, there are substantial medical reasons for not allowing patients to become self-medicating, then it would be foolish to advocate and encourage people in that situation to take greater control over their conditions. The assumption that dependency is necessarily a bad thing is not a viable one, and a theme that is returned to below. 
All of this has a rather Foucaultian edge to it, disciplining the long-term ill to look after themselves and reduce their demands on drugs (and hence drug expenditure) and on health professional time to attempt to free up doctors' and nurses' resources towards other goals (Wilson, 2001). The process of actively 'empowering' patients with long-term conditions appears to take up a considerable amount of resources, with little evidence to suggest that this commitment decreases over time (Paterson, 2001). The Expert Patient model of care can easily be presented as a regressive rather than progressive policy for shifting medical expense and liability away from the state.

\section{CONCLUSION - DEPENDENCY, AGENCY AND EXPERT PATIENTS}

Underpinning much of the analysis above is Labour's extreme discomfort with dependency. The idea of the 'dependency culture' appeared in the 1970s and 1980s as part of the discourse of the new right, and is associated with writers such as Charles Murray (1984) and the idea that the 'underclass' was in danger of destroying society. Murray is significant because he located that underclass not in terms of their socio-economic structural position, but in terms of their behaviour. Among the underclass, the work ethic is weak, social expectations are low, and there is a reduced sense of discipline and responsibility. This, in turn according to Murray, leads to children being born out of marriage, a vandalising of the physical environment and high rates of crime. Murray argues that 'the poor and non-poor alike use the same general calculus in making decisions' (Murray, 1984, p. 155). These groups are choosing to maximise their behaviour within the rules the state has created, with an underclass developing as a consequence of badly designed benefit systems (Field, 1997).

As such, the 'underclass', according to Murray, appears to be behaving in a highly reflexive way, being prepared to challenge the rules of behaviour expected within society (commit crime) as well as exploit the rules to receive extra benefits (young unmarried women have children in order to receive better housing). Murray and Giddens appear to hold a remarkably similar model of agency central to their accounts of human behaviour, assuming a highly reflexive actor at their core. Giddens' policy prescription has the state acting as a sort of risk adjuster, educating and paying benefits to those who need to move career or gain additional qualifications, whereas Murray argues that action must take place at community level, free from state interference, to resolve the problem. What both writers agree on, however, is that individuals hold the power within them to 'escape' from their present circumstances, should they choose to do so. Whereas Murray tends to assume 
'knavish' (Le Grand, 1997) behaviour on the part of benefit recipients (albeit in response to perverse incentive structures), Giddens takes a more optimistic view that we can all become 'knights'. The dependency culture, in the view of both writers, is something that must be overcome, but through different mechanisms according to their view of human nature.

But dependency holds a positive as well as negative meaning, with important analytical implications. Hoggett's (2000) study of dependency suggests that many of the most positive human emotions love and trust, for example - are based on placing ourselves as being dependent to some degree upon another. Vulnerability is 'something that is essential to our nature as human beings' (p. 176). Human development is not just about the development of the capacity to become autonomous from others, but about combining autonomy with the ability to learn on how to depend on others 'Just as we need to learn how to use our own authority we also need to learn how to use and benefit from that authority of others which is derived from skill, knowledge and experience which we do not have' (pp. 176-177). A statement making the central problem with the Expert Patient clearer, as presently formulated, would be hard to find.

It is necessary to strike a balance between caring and empowering - if only the former is considered there is a danger of imposing a Foucaultian discourse of discipline on Expert Patients, where they regard any dependency upon the medical profession as failure. Patients, with the experience and knowledge they have acquired about their conditions, clearly can make a positive contribution toward their own care, but this must be tempered with a recognition of the dependency that we place upon doctors - dependency in a positive, caring sense. If the state continually refers to the resource savings that might be achieved through greater use of the Expert Patient programmes, this puts the medical profession under considerable pressure to introduce the programme where it is inappropriate.

Within the category of the long-term sick, there exists a variety of conditions, and within those conditions a wide range of individual responses to their conditions, based on a wide variety of factors. To group those with long-term conditions, and present the possibility that improvements in their condition might come relatively easily from becoming an Expert Patient, is both patronising and unrealistic, making assumptions about human nature apparently based on similar assumptions to Giddens' structuration theory only too common in the Third Way.

As well as this, the state does not require just any form of reflexivity, but a reflexivity that accepts the existing rules of the game, and attempts to make the best of them (what Hoggett (2001) calls first-order agency) rather than attempting to challenge the rules themselves (second-order agency) is not 
encouraged. This flies in the face of much of the rhetoric of welfare policy under New Labour and sheds new light on the patronising nature of policies such as 'earned autonomy' in the NHS (Secretary of State for Health, 2000), where relief from an increasingly harsh inspection regime (Department of Health, 2001a; Secretary of State for Health, 2002) and access to increased funding are allowed for an elite percentage of Trusts that demonstrate, through government statistical returns, that they are its highest performing organisations. Locality is allowed, but only if you obey extensive national rules (Hoque et al., 2004).

The long-term ill start with the disadvantage of having to manage a condition that may involve use of medication in imprecise circumstances and frequent consultation with the medical profession. Those who suffer from physical or psychological disabilities are often not in the best position to negotiate their care. For the government to pretend that these inequalities do not exist is hugely problematic, and perhaps even dangerous. For an elderly pensioner living in a rural community (by definition an expensive patient to treat, and so, one supposes, an excellent candidate to become an Expert Patient), the support systems may not be clear or easily available. In this case, a lengthy trip might be required to see a health professional to enquire about drug usage, for example, and increased isolation might become a real possibility. To treat the long-term ill in simple medical terms does not work; health professionals often perform a vital social role in linking those with long-term debilitating conditions with local communities through community nurses, for example; therefore, to force greater independence upon this group would be an error on both medical and social grounds.

\section{Acknowledgements}

Thanks to Paul Hoggett for his help and encouragement in developing these ideas while I was employed at the University of the West of England, Bristol, where I was also supported in this research with a small grant from the Centre for Economic and Social Research (CESAR).

\section{REFERENCES}

Archer M (1995). Realist Social Theory: The Morphogenetic Approach. Cambridge University Press: Cambridge.

Baker C, Stern P (1993). Finding meaning in chronic illness as the key to self care. Canadian Journal of Nursing 25: 23-26.

Barlow J, Barefoot J (1996). Group education for people with arthritis. Patient Education and Counselling 27: 257-267.

Barlow J, Williams B (1999). "I now feel that I'm not just a bit of left luggage”: the experiences of older women with arthritis attending a Personal Independence Course. Disability and Society 14: 53-67. 
Barlow J, Williams B, Wright C (1999). Instilling the strength to fight pain and get on with life: learning to become and arthritis self-manager through an adult education programme. Health Education Research 14: 533-544.

Bernstein R (1989). Social theory as critique. In: Held D, Thompson JB (eds). Social Theory of Modern Societies: Anthony Giddens and His Critics. Cambridge University Press: Cambridge, pp 19-33.

Bourdieu P (1990). The Logic of Practice. Polity Press: Cambridge.

Bourdieu P (1991). Language and Symbolic Power. Polity Press: Cambridge.

Bourdieu P (1998). Practical Reason: On the Theory of Action. Polity Press: Cambridge.

Burrows R, Nettleton S (2000). Reflexive modernisation and the emergence of wired self-help. In: Burrows R, Pleace N (eds). Wired Welfare? Essays on the Rhetoric and Reality of e-Social Policy. Centre For Housing Policy Discussion Paper: York, pp 9-22.

Clarke J, Newman J (1997). The Managerial State. Sage: London.

Craib I (1992). Anthony Giddens. Routledge: London.

Deacon A, Mann K (1999). Agency, modernity and social policy. Journal of Social Policy 28: 413-435.

Department of Health (1999). Our Healthier Nation - Saving Lives. Department of Health: London.

Department of Health (2001a). NHS Performance Ratings: Acute Trusts 2000/2001. Department of Health: London.

Department of Health (2001b). The Expert Patient: A New Approach to Chronic Disease Management for the 21st Century. Department of Health: London.

Department of Health (2002). Shifting the Balance of Power within the NHS: Securing Delivery. Department of Health: London.

Department of Health (2004). Choosing Health: Making Healthier Choices Easier. HMSO: London.

Donaldson L (2003). Expert patients usher in a new era of opportunity for the NHS. British Medical Journal 326: 1279-1280.

Field F (1997). Self-interest and collective welfare. In: Field F (ed). Reforming Welfare. Social Market Foundation: London, pp 11-34.

Fox NJ, Ward KJ, O'Rourke AJ (2005). The 'expert patient': empowerment or medical dominance? The case of weight loss, pharmaceutical drugs and the Internet. Social Science \& Medicine $\mathbf{6 0}$ : 1299-1309.

Gaze H (2000). A knowledge born of experience. Nursing Times 96: 15.

Giddens A (1979). Central Problems In Social Theory. MacMillan: London.

Giddens A (1984). The Constitution of Society. Polity: Cambridge.

Giddens A (1989). A reply to my critics. In: Held D, Thompson J (eds). Social Theory of Modern Societies: Anthony Giddens and his Critics. Cambridge University Press: Cambridge, pp 249-301.

Giddens A (1991). Modernity and Self-Identity. Polity: Cambridge.

Giddens A (1994a). Beyond Left and Right: The Future of Radical Politics. Polity Press: Cambridge.

Giddens A (1994b). Living in A Post-traditional Society. In: Beck U, Giddens A, Lash S (eds). Reflexive Modernisation. Polity: Cambridge, pp 56-109.

Giddens A (1998). The Third Way: The Renewal of Social Democracy. Polity: Cambridge.

Giddens A (2002). What Now for New Labour? Polity: Cambridge.

Giddens A (2007). Over to you, Mr. Brown. Polity Press: Cambridge.

Greener I (2002). Agency, social theory and social policy. Critical Social Policy 22: 688-706.

Greener I, Mannion R (2006). Does practice-based commissioning avoid the problems of fundholding? British Medical Journal 333: 1168-1170.

Greener I, Powell J (2003). Health authorities, priority-setting and resource allocation: a study in decision-making in new labour's NHS. Social Policy and Administration 37: 35-48.

Gregson N (1989). On the (ir)relevance of structuration theory to empirical research. In: Held D, Thompson J (eds). Social Theory of Modern Societies: Anthony Giddens and his Critics. Cambridge University Press: Cambridge.

Hoggett P (2000). Emotional Life and the Politics of Welfare. Palgrave: London. 
Hoggett P (2001). Agency, rationality and social policy. Journal of Social Policy 30: 37-56.

Hoque K, Davis S, Humphreys M (2004). Freedom to do what you are told: senior management team autonomy in an NHS acute trust. Public Administration 82: 355-376.

Illman J (2000). Patient power. Nursing Times 96: 28-30.

Le Grand J (1997). Knights, Knaves or Pawns? human behaviour and social policy. Journal of Social Policy 26: 149-169.

Lorig K (2002). Partnerships between expert patients and physicians. The Lancet 359: 814-815.

Lorig K, Stewart A, Ritter P, Gonzalez V, Laurent D, Lynch J (1996). Outcome Measures for Health Education and Other Health Care Interventions. Sage: Thousand Oaks.

Multiple Sclerosis Society (2003). Measuring Up: Experiences of people with MS of health services. MORI/Multiple Sclerosis Society: London.

Murray C (1984). Losing Ground. Basic Books: New York.

Paterson B. (2001). The myth of empowerment in chronic illness. Journal of Advanced Nursing 34(5): 575-581

Peterson A, Lupton D (1996). The New Public Health: health and self in the age of risk. Sage: London. Ritzer G (1996). Sociological Theory. McGraw-Hill: London.

Rogers A, Bower P, Gardner C, Gately C, Kennedy A, Lee V, Middleton E, Reeves D, Richardson G (2006). The National Evaluation of the Pilot Phase of the Expert Patient Programme: Final Report. National Primary Care Research and Development Centre: Manchester.

Secretary of State for Health (1992). The Health of the Nation: A Strategy for Health in England. HMSO: London.

Secretary of State for Health (2000). The NHS Plan: A Plan for Investment, A Plan for Reform. HMSO: London.

Secretary of State for Health (2002). Delivering the NHS Plan: Next Steps on Investment and Reform. HMSO: London.

Shaw I (2002). How lay are lay beliefs? Health 6: 287-299.

Shaw J, Baker M (2004). “Expert patient” - dream or nightmare? British Medical Journal 328: 723-724.

Swift T, Dieppe P (2005). Using expert patients' narratives as an educational resource. Patient Education and Counseling 57: 115-121.

Tattersall R (2002). The expert patient: a new approach to chronic disease management for the twenty-first century. Clinical Medicine 2: 227-229.

Taylor-Gooby P, Sylvester S, Calnan M, Manley G (2000). Knights, knaves and gnashers: professional values and private dentistry. Journal of Social Policy 29: 375-395.

Thompson J (1989). The theory of structuration. In: Held D, Thompson J (eds). Social Theory of Modern Societies: Anthony Giddens and his Critics. Cambridge University Press: Cambridge, pp 56-76.

Twigg J (1997). Deconstructing the "social bath": help with bathing at home for older and disabled people. Journal of Social Policy 26: 211-232.

Westergaard J (1999). Where does the third way lead? New Political Economy 4: 429-436.

Wilson P (2001). A policy analysis of the Expert Patient in the United Kingdom: self-care as an expression of pastoral power? Health and Social Care in the Community 9: 134-142.

Wilson P, Kendall S, Brooks F (2006). Nurses' responses to expert patients: the rhetoric and reality of self-management in long-term conditions: a grounded theory study. International Journal of Nursing Studies 43: 803-818.

Wilson T, Buck D, Ham C (2005). Rising to the challenge: will the NHS support people with longterm conditions? British Medical Journal 330: 657-661.

Wootton I, Wood V, Cook F (2008). Who wants expert patient programmes for chronic mechanical spinal pain?: an investigation into the value of, and recruitment to, an expert patient programme as part of the physiotherapy management of chronic spinal pain. Physiotherapy 94: 78-84. 